\title{
Investigando as Habilidades de Processamento Linguístico Infantil: A Aquisição da Distinção Massivo/ Contável em Português Brasileiro
}

José Ferrari-Neto (UFPB)

\section{Resumo}

Este trabalho investiga o papel das informações sintáticas e semânticas presentes no input linguístico no processo de aquisição da distinção entre nomes massivos e contáveis em português brasileiro (PB), em especial as informações relativas à expressão do número gramatical. Para o reconhecimento da distinção mass/count em $P B, e ́$ importante a manifestação morfológica relativa a número que se manifesta nos elementos do Determiner Phrase (DP). Pode-se assumir a hipótese de que uma criança seja capaz de perceber a presença/ ausência do morfema de número, tomando esta oposição como indicativa de expressão massiva ou contável. Por outro lado, a presença de nomes nus em posições argumentais no PB torna o input ambíguo no que se refere a mass e count nouns. Tal situação constitui um problema para a criança que adquire o PB. Nesse caso, assumiu-se a hipótese de que a criança usa informação não morfológica, mas sim semântica (contextual), na interpretação de DP's ambiguos. Portanto, os objetivos deste estudo são a) verificar se a criança toma a presença do morfema de número como indicativa de leitura contável; e b) verificar como a criança procede na interpretação de DP's ambíguos. Usando o paradigma metodológico da Seleção de Imagens, testaram-se dois grupos de crianças (um na faixa de 36 meses de idade média, e outro na faixa de 60 meses) e um grupo de adultos, com os resultados sustentando a idéia de que tanto informação morfossintática quanto informação semântico- 
-contextual são relevantes na aquisição de nomes massivos e contáveis em PB.

Palavras-chave: aquisição, contável, massivo.

\section{Introdução}

A expressão linguística da distinção mass e count é observada em muitas línguas modernas. $O$ inglês e o português são casos típicos de línguas em que esta distinção se apresenta. Temse associado a divisão entre mass e count nouns à distinção entre nomes de substâncias e nomes de objetos, sendo estes últimos constantes da classe dos count nouns, e os primeiros à classe dos mass nouns. Um exame rápido desta classificação, contudo, revela a sua precariedade: palavras como furniture, embora designe um conjunto de objetos, classifica-se como mass noun; outras, como beer, que claramente se refere a uma substância em frases como there is beer all over the floor, aparece flexionado em uma sentença como we ordered three beers, propriedade atribuída a count nouns. Uma outra associação feita foi a que relacionava mass e count nouns às categorias contável e incontável, colocando-se os mass nouns no grupo dos substantivos incontáveis e os count nouns no grupo dos substantivos contáveis. Todavia, uma vez mais se encontraram casos em que associação falhou: açúcar em português comportase como quase sempre como incontável, mas, em sentenças como no intestino digerem-se açúcares e ácidos graxos, seu comportamento é de contável. Outros exemplos como este também podem ser observados em inglês em outras línguas.

No que diz respeito à aquisição da linguagem, a distinção entre mass e count nouns acarreta problemas bastante interessantes, principalmente para uma teoria de aquisição focada no modo como criança processa material linguístico à sua volta. As questões fundamentais que se colocam são o que a criança tem de adquirir no tocante a essa distinção, que habilidades/conhecimentos ela já tem de possuir para que esta aquisição ocorra naturalmente e que tipo de informação constante nos dados linguísticos primários a que ela tem acesso se faz relevante para este processo. Portanto, o presente trabalho investiga o papel das informações morfossintáticas e semânticas presentes no input linguístico no processo de aquisição da distinção entre nomes massivos e contáveis em português brasileiro (PB), explorando, por outro lado, as habilidades de compreensão e distinção perceptuais apresentadas pela criança em fase de aquisição, consideradas como fundamentais no processo de aquisição da linguagem, na medida em que permitem a ela reconhecer as informações relevantes para a aquisição de sua língua. 
Investigando as Habilidades de Processamento Linguístico Infantil:

A Aquisição da Distinção Massivo/Contável em Português Brasileiro

O estudo aqui apresentado tem a seguinte organização. A seção 2 apresenta um resumo das principais correntes teóricas sobre a questão em tela, de modo a poder situar o framework teórico no qual este trabalho se situa, além de mostrar alguns estudos experimentais realizados anteriormente, com vistas a melhor ilustrar a problemática que envolve a aquisição de nomes massivos e contáveis. A seção 3 traz uma caracterização do modo como as categorias massivo e contável se realizam em português, permitindo assim uma visão do que deve ser adquirido por uma criança aprendendo o PB. A seção 4 detalha as questões aqui enfrentadas, além de descrever o procedimento experimental utilizado com vistas a prover evidências empíricas sobre a questão dos massivos e contáveis. A seção 5 mostra os resultados e os discute.

\section{Posições Teóricas sobre os Mass e Count Nouns:}

As posições teóricas sobre a distinção massivo/contável apresentam uma multiplicidade de visões. Segundo Joosten (2003), uma das razões para esta variação é que os linguistas e os filósofos que têm se dedicado ao estudo de mass e count nouns apresentam dificuldades em definir claramente os seus critérios, o que acarreta a convergência de diferentes níveis de análise linguística no tratamento da questão. Joosten propõe então que o problema da distinção entre nomes contáveis e massivos seja estudado sob quatro pontos de vista diferentes, tomados separadamente.

O primeiro ponto de vista adotado por Joosten seria o gramatical, de acordo como qual a oposição mass/count apresenta reflexos gramaticais bastante visíveis. A existência de casos como os relatados na Introdução levou os linguistas a não mais associarem mass e count nouns às categorias substância/objeto e incontável/ contável, ou a qualquer outra categoria de base semântica. Antes, eles passaram a preferir apontar as características e propriedades puramente gramaticais relacionadas a ambas as classes em questão. Assim, uma série de características morfológicas e sintáticas foi associada a mass e count nouns. Entretanto, ainda que se possam determinar com relativa clareza e segurança as diferenças entre mass nouns e count nouns, no tocante a suas propriedades morfossintáticas, não são poucas as questões decorrentes da existência de tal separação. Em realidade, duas objeções são apontadas por Joosten com relação ao ponto de vista gramatical. A primeira é que parece improvável que nomes massivos como água, ouro e fumaça ou contáveis como flor, carro e cachorro assim o sejam apenas por coincidência - ao contrário, eles parecem indicar que há uma tendência geral para nomes massivos se referirem a substâncias e nomes contáveis se referirem a objetos e seres animados. A segunda é que o ponto de vista gramatical parece pressupor uma correlação um-para-um entre forma gramatical e significação, o que nem sempre acontece. Barner \& Snedeker (2005), em um estudo experimental sobre a aquisição de mass e count nouns, 
apontam o fato de que nomes com sintaxe típica de mass fazerem também referência a indivíduos, além de substâncias.

Estudos sobre mass e count nouns costumam adotar igualmente um ponto de vista ontológico em suas teorizações. Sob esta visão, a distinção massivo/contável decorre de distinções operadas entre entidades reais do mundo, ou seja, entre referentes extralinguísticos. Quine (1960) afirma que mass nouns têm "referência cumulativa", isto é, qualquer soma de uma entidade Xé um $X$, fato que não ocorre com os count nouns. Cheng (1973) postula que mass nouns apresentam "referência distributiva": qualquer parte de um todo de um objeto massivo que é X é um X. Por fim, Ter Meulen (1981) propõe que mass nouns possuem "referência homogênea", isto é, partes de uma entidade $X$ apresentam as mesmas propriedades de $X$, podendo ser referidas como X. Para estas três propriedades, cumulatividade, distributividade e homogeneidade, $\mathrm{o}$ mundo real é a base de classificação, portanto, são as propriedades físicas dos objetos e dos seres referidos que determinam se um nome deve ser classificado como massivo ou contável. Esta forma de teorização apresenta, entretanto, alguns problemas. Se são as propriedades das entidades do mundo extralinguístico que determinam a classificação de um nome, então é lícito prever que diferentes línguas apresentarão a mesma classificação para as mesmas entidades. Todavia, não é isso que se observa em um exame da distribuição dos nomes entre classes de nomes massivos e contáveis nas diferentes línguas. Translinguisticamente, aponta-se uma variação da categorização dos nomes em classes de mass e count nouns (CHIERCHIA, 2003). Um outro problema decorrente da adoção do ponto de vista ontológico é o fato de que os conceitos de cumulatividade, distributividade e homogeneidade são difíceis de serem aplicados a substantivos abstratos tais como crise, qualidade ou tristeza. O ponto de vista ontológico pode ser aplicado com maior sucesso a substantivos concretos, que designam objetos tangíveis ou perceptíveis, mas falha quando aplicado a nomes abstratos, embora também estes possam ser classificados em contáveis e massivos. Por fim, o ponto de vista ontológico não dá conta de explicar como um nome que se refere a uma mesma entidade do mundo real pode ser usado tanto como mass quanto como count, em uma mesma língua.

A existência de pares como os acima listados evidencia que os nomes são classificados em uma ou outra classe conforme o modo como são conceptualizados pelos falantes de uma dada língua, refletindo, portanto, a visão de mundo característica do povo usuário da língua. Tal afirmação constitui a base do terceiro ponto de vista proposto por Joosten, o ponto de vista semântico/conceptual, segundo o qual as distinções gramaticais entre massivos e contáveis não se baseiam diretamente na realidade extralinguística, mas no modo como esta realidade é conceptualizada pelos usuários de uma língua. Algumas abordagens sobre a separação 
entre mass e count nouns sugerem que tal distinção é um reflexo, na linguagem, do modo como o mundo é conceptualizado e organizado pelos falantes de uma dada língua. As propriedades morfossintáticas sumarizadas acima seriam, de acordo com esta visão, as manifestações linguísticas das propriedades semânticas extralinguísticas das coisas às quais os nomes se referem, conforme o modo como os falantes de uma dada língua as conceptualizam. Dentre os trabalhos relevantes desta linha, pode-se citar o de Macnamara (1982), o qual sugere que count nouns se referem a coisas que possuem contornos (shapes) característicos, ao passo que mass nouns se referem a coisas que se aglutinam (coalesce). $\mathrm{O}$ problema com esta proposta é que ela não dá conta de explicar por que nomes que não possuem contornos característicos como puddles e clouds são count nouns e nomes como crowd são mass nouns.

A maior parte dos trabalhos sobre aquisição de mass e count nouns que seguem uma orientação semântico-conceptual tendem a tratar a aquisição de nomes massivos e contáveis atreladamente ao desenvolvimento da cognição em geral. Eles sustentam que há uma interação entre o modo como a criança desenvolve categorias semânticas gerais, a partir de sua experiência com a realidade, e identifica os membros destas categorias na linguagem. Assumese questão as propriedades de referência dos nomes que guiam a criança na identificação de categorias. Middleton et al. (2004), em tarefas experimentais com adultos, fornecerem evidências favoráveis à hipótese da cognição individuada, afirmando que os falantes adultos conceptualizam os referentes de count nouns como entidades individuais, ao passo que conceptualizavam os referentes dos mass nouns como entidades não-individuais. Um outro estudo nesta mesma linha é o de Bloom (1994) sobre aquisição de nominais por falantes de inglês. Ele postula que a criança mapeia as categorias como mass noun e count noun de categorias semânticas abstratas, e este mapeamento atua como restrição às inferências que podem ser feitas sobre o significado das palavras. Portanto, de acordo com a abordagem semântica-conceptual, a aquisição de mass e count nouns baseia-se não em uma análise distribucional por parte da criança adquirindo uma língua, mas na compreensão que esta criança tem do sentido dos nomes.

Um ponto convergente em todos os trabalhos que assumem uma visão semântica da distinção mass/count é que eles parecem assumir algum tipo de conhecimento inato relativo à capacidade de a criança proceder a tal classificação. Deste modo, a criança disporia de um conhecimento inato que a tornaria capaz de categorizar nomes que denotam espécies de indivíduos como contáveis e nomes que designam substâncias como massivos. A crítica que se pode fazer a esta abordagem é que, na realidade, a criança não aprende a classificar um nome como mass ou como count: o que de fato a criança procede é a menos uma classificação e mais um aprendizado do modo como um nome pode ser usado, se seguido 
de marcadores gramaticais específicos ou não, e os sentidos que se podem atribuir a um e a outro usos. De acordo com Nicolas (1996), uma criança não classifica erroneamente um nome como mass ou como count, já que não há classificação propriamente dita: o que ocorre é um uso inadequado de marcadores gramaticais de um ou outro tipo, devido ao fato de que a criança ainda não percebeu exatamente a referência destes nomes ou destas estruturas.

A grande objeção que se pode apontar para uma teorização sobre mass e count nouns baseada em conceptualização é que tal ponto de vista torna complicada a explicação para diferentes conceptualizações para objetos e seres bastante semelhantes. Um exemplo seria o da palavra ervilha, que é classificada como contável em português (uma ervilha, duas ervilhas), o mesmo não ocorrendo como a palavra arroz, que em português insere-se entre os massivos ("um arroz, *dois arrozes). Ademais, o ponto de vista semântico-conceptual, semelhantemente à visão ontológica, não permite explicar como um nome referente a uma mesma entidade do mundo real pode ser usado tanto como mass quanto como count, por falantes de uma mesma língua.

O último dos pontos de vista sugeridos por Joosten seria o contextual, conforme o qual não é uma propriedade dos nomes de per se serem massivos ou contáveis, mas sim das expressões referenciais das quais eles fazem parte, ou seja, dos NP's ou DP's. Assim, um nome não deve ser classificado como mass ou como count, antes a distinção entre estas duas categorias é determinada pelos quantificadores e determinantes que são utilizados por cada tipo de nome, ou ainda pelos operadores semânticos que atuam sobre os NP's e DP's determinando leituras contáveis ou não para estas expressões. Percebe-se uma aproximação entre esta visão e o ponto de vista gramatical, exposto acima. O ponto fraco da visão contextual é o fato de ela não explicitar as razões pelas quais determinados contextos favorecem a ocorrência de nomes massivos, ao passo que outros contextos favorecem o aparecimento de nomes contáveis, como, por exemplo, o fato de substantivos coletivos ou abstratos favorecerem leitura massiva, e substantivos concretos privilegiarem interpretação contável. No tocante à aquisição de mass/count nouns, o que os estudos experimentais nesta linha sugerem é uma sensibilidade da criança à forma fônica dos determinantes específicos dos nomes de massa e dos nomes contáveis (notadamente em inglês), sem que se possa afirmar, a partir daí, que a criança esteja procedendo a uma distribuição dos nomes em classes distintas. Além do mais, uma análise distribucional de per si não seria suficiente para se estabelecer a distinção massivo contável, já que nomes com sintaxe massiva podem ter referência contável, conforme apontam Chierchia (1998) e Barner \& Snedeker (2005), sem mencionar o fato de não ficar claro que capacidades perceptuais e procedimentais a criança tem de possuir para reconhecer os diferentes determinantes. Por fim, 

se se postular que diferentes determinantes projetam diferentes estruturas sintáticas para mass e para count nouns, será preciso conceber um mecanismo de análise sintática inato, tipo parser, responsável por processar enunciados e atribuir uma estrutura sintática a eles, o que eliminaria o ponto central da abordagem distribucional, em favor da abordagem inatista.

O problema da aquisição da linguagem, no que toca à distinção mass/count não pode ser considerado exclusivamente em termos semânticos ou distribucionais. Como bem aponta Chierchia (2003) tal questão não é de cunho exclusivamente semântico (e nem conceptual, poder-se-ia acrescentar), nem de natureza estritamente linguística, já que as crianças não adquirem mass e count nouns considerando unicamente a informação semânticoconceptual; tampouco o fazem apenas observando comportamentos sintáticos e propriedades de distribuição. Uma teoria baseada na interação sintaxe-semântica se faz necessária.

A despeito de a proposta de Joosten sugerir que o estudo da distinção massivo/contável deva ser feito considerando-se quatro pontos de vista, tomados isoladamente, acredita-se ser possível conferir a este tópico um tratamento unificado. Uma tal unificação de abordagens permitiria melhores considerações acerca da definição do que vem a ser a oposição mass/count, bem como acerca do modo como esta distinção é adquirida pelos falantes de uma língua. Assim, pode-se prever que, na aquisição de massivos e contáveis em $\mathrm{PB}$, traços semânticos do nome podem influenciar a interpretação do DP. Por outro lado, se a distinção massivo/ contável se apresenta apenas em certos ambientes, então a criança adquirindo essa distinção tem de perceber esses ambientes, extraindo deles informação relevante nesse sentido. Assumindose que a informação morfológica relativa a número possui papel relevante no estabelecimento de distinções relativas a mass e count nouns, uma vez que ela pode conferir leitura massiva ou contável dos DPs, tem-se que a percepção do morfema de plural é crucial na identificação da oposição massivo/contável no PB. Assim, informação fônica, correspondente ao morfema de número, e informação semântica, advinda dos traços semânticos da raiz, seriam usadas pela criança ao adquirir uma língua, podendo ser utilizadas em situações e momentos distintos do processo de aquisição, em especial no caso de DPs ambíguos quanto a mass/ count. Os experimentos aqui relatados visam justamente a investigar essa possibilidade.

\section{A Expressão da Distinção Mass/Count em PB}

Os estudos descritivos sobre a expressão da distinção entre nomes massivos e contáveis em PB apresentam em seu bojo uma controvérsia, a qual diz respeito ao fato de se considerar se há ou não manifestação lexical da oposição mass/count. Dito de outro modo, trata-se de decidir se existem ou não nominais contáveis 
ou massivos em PB. Estudos como o de Simões (1992), Camacho e Pezatti (1996), Neves (2000) e Paraguassu (2005) defendem a idéia de que há distinção lexical, ao passo que trabalhos como o de Bluhdorn \& Favaretto (2000), Muller (2002) e Bluhdorn, Simões e Schmaltz (2007) apresentam a visão de que nomes massivos e contáveis não se distinguem em PB. Bluhdorn \& Favaretto (2000) argumentam a favor da inexistência de nomes contáveis no PB. Usando como evidência a distribuição dos totalizadores nominais cada e todo e dos quantificadores de contagem e de medição, os autores chegaram à conclusão de que $\mathrm{o} P \mathrm{~B}$ possui apenas substantivos não-contáveis e neutros em relação à contabilidade, numa proposta semelhante a de Barner \& Snedecker (2005 a,b) para o inglês. Nomes massivos combinam-se com o totalizador todo e com quantificadores de medição, mas não com quantificadores de contagem nem com o totalizador distributivo cada. Nomes neutros são combináveis com qualquer totalizador e quantificador. Assim, para esses autores, o PB não possui substantivos contáveis. O traço [+contável] só existe em nível do DP, como contribuição semântica do morfema de plural ou de um quantificador distributivo ou de contagem.

Uma idéia semelhante encontra-se em Muller (2002), a qual também propõe que não haja substantivos contáveis em PB. Segundo Muller, a denotação básica dos nomes comuns em PB é de massa. A argumentação centra-se no comportamento dos genéricos singulares de tipo bare, como em Lagartixa sempre perde seu rabo e Jorge sempre lê revista depois do jantar. Para Muller, além de não terem marcas de número, tais construções têm comportamento semelhante a expressões com denotações não-discretas. Muller sustenta que, no primeiro exemplo, o possessivo anafórico seu herda de seu antecedente a ausência de marcas de número. No segundo, além de não haver marca de número, fica evidente que Jorge poderá ler qualquer quantidade do material de leitura revista; pode ser o caso de que ele leia duas revistas ou até mesmo apenas algumas páginas de uma revista. Além disso, Muller demonstra que os singulares bare não oferecem contextos adequados para elementos que exigem individuação, como o emprego de recíprocos - *Brasileiro detesta um ao outro - ou de quantificadores distributivos - *Cada aluno leu livro. Para Muller, será necessária a presença de um operador de singularidade ou de pluralidade para que o DP tenha a propriedade de atomicidade necessária a uma interpretação como contável.

Bluhdorn, Simões e Schmaltz (2007) discutem a classificação dos nomes e DP's massivos e no alemão e no PB, propondo um modelo de estrutura, aplicável em princípio a ambas as línguas, em que a leitura contável é construída composicionalmente em nível do DP, mediante a combinação dos traços [ \pm individuado], [ \pm incrementado] e [ \pm delimitado]. O valor do primeiro traço é fixado pelo quantificador, o do segundo, pelo número e o do terceiro, 
Investigando as Habilidades de Processamento Linguístico Infantil:

A Aquisição da Distinção Massivo/Contável em Português Brasileiro pelo substantivo. Na língua alemã, os três traços contribuem para a constituição da leitura massiva, ao passo que em PB apenas os dois primeiros mostram-se produtivos, enquanto o terceiro é irrelevante. Isso corresponde a dizer que não se distinguem nomes contáveis e massivos no léxico do PB.

Numa visão oposta, o trabalho de Simões (1992) apresenta a distinção entre nomes massivos e contáveis em termos de classificação semântica, em detrimento de uma oposição de natureza morfossintática. Simões procurou demonstrar que todos os nomes do PB podem combinar-se tanto com indicadores de leitura contável quanto de leitura massiva, havendo apenas algumas restrições lexicais, o que conduz à proposta de que a distinção opera num nível chamado semântico formal, sendo implementada por meio da presença de pluralização e de certos tipos de quantificadores e determinantes dentro do DP. Num nível mais próximo ao léxico, denominado referencial, certos nomes (como triângulo) apresentariam traços de contabilidade, enquanto outros nomes não o fazem, o que explica a estranheza de certas combinações (tais como muito triângulo). Desse modo, ainda que sinalize para a ausência de uma oposição distribucional sistemática, Simões manteve a hipótese de que os nomes apresentem marcas de contabilidade em PB.

Por sua vez, Camacho \& Pezatti (1996) investigaram a natureza do traço [ \pm contável] de acordo com as possibilidades de combinação dos nomes do PB com determinantes e quantificadores em DP's referenciais e não-referenciais. O trabalho registrou semelhanças entre o PB e as chamadas línguas classificadoras, por se valer de substantivos secundários na expressão de noções de dimensão (individuação, conjunto ou massa) junto a nomes massivos em construções tais como um fio de cabelo. Entretanto, Camacho \& Pezatti também mantiveram a distinção entre nomes massivos e contáveis em PB.

Neves (2000) aborda a expressão da distinção mass/count em PB sob a ótica da referenciação, ou seja, como questão pragmática. Neves afirma que, embora as categorias massivo e contável possam ser explicadas em termos de uma propriedade lexical (com os nomes marcados no léxico com os traços [- contável] e [-contável]), a ativação dessa propriedade só se faz na função de referenciação. Mantendo, portanto, a distinção entre nomes massivos e contáveis como propriedade lexical, Neves descreve como as combinações de nomes com determinantes, quantificadores e morfemas de número podem levar à "flutuação" entre as duas categorias. A descrição de Neves (2000) aparece sumarizada a seguir:

I - São nomes contáveis (em PB): a) substantivo plural que identifique mais de uma unidade discreta; b) substantivo plural que permita uma oposição com um singular; c) substantivos determinados por quantificador não numerador que opera acréscimo de uma grandeza (ex.: outro); 
d) substantivos determinados por quantificador não numerador que opera distribuição (ex.: todo e qualquer); e) substantivos determinados por quantificador não numerador do tipo de muito e pouco, quando o significado é plural; f) ) substantivos determinados por quantificador numerador cardinal; g) substantivos determinados por determinante indefinidor (artigo indefinido ou pronome indefinido).

II - São nomes massivos (em PB): a) Substantivos que indiquem massa ou substância; b) substantivos abstratos (desde que não indiquem nomes do resultado ação ou do processo); c) substantivos no plural (quando a forma singular não se opõe com a forma plural); d) substantivos pluralia tantum; e) substantivos determinados por quantificador não numerador do tipo muito/pouco/mais/menos.

Neves (2000) destaca a grande flutuação de categorias, com nomes passando frequentemente uma categoria à outra, como é o caso dos nomes que a operação de pluralização converteu de massivos para contáveis (preparamos as carnes) ou que a perda da pluralização converteu de contável para massivo. Segundo Paraguassu (2005), o PB, assim como o chinês, é uma língua que apresenta distinção lexical entre nomes massivos e contáveis, o que equivale a dizer que no $\mathrm{PB}$ existe uma distinção entre nomes que possuem e nomes que não possuem partes mínimas em sua denotação (cf. DOETJES, 1997). De acordo com essa mesma autora, a distinção massivo/contável não se manifesta no nível do nome, sendo visível apenas em ambientes marcados para contabilidade. Em PB, tal marcação se dá por meio da morfologia de número. Segundo Muller (2002), a morfologia de número no PB funciona como um operador sobre a denotação do sintagma nominal, definindo-o para número. Há, para Muller, dois operadores de número no PB: SG (singular) e PL (plural), os quais conferem interpretação contável sobre os nomes sobre os quais atuam. Paraguassu (2005) aponta como operadores de singularidade o quantificador cada e os determinantes $o(a)$, um(a) (ex.: Eu vendi cada anel/*anéis que eu ganhei); e como operadores de pluralidade o quantificador vários e os determinantes os(as), um(ns), bem como o morfema de plural. Casos em PB em que os nomes massivos apresentam morfologia de número não indicam mudança de categoria lexical, mas sim mudança de significado - nomes massivos sob escopo de um operador de plural ou singular recebem ou interpretação de maneira taxionômica ou a unidade é estabelecida contextualmente, como nos exemplos abaixo (cf. PARAGUASSU, 2005):

João comprou dois vinhos.

a. João comprou dois tipos de vinho.

b. João comprou duas garrafas/taças... de vinho. 
Eu ganhei um vinho muito bom.

a. Eu ganhei um tipo de vinho muito bom.'

b. Eu ganhei uma garrafa/taça... de vinho muito boa.'

Assumindo-se, de acordo com Simões (1992), Camacho e Pezatti (1996), Neves (2000) e Paraguassu (2005), a existência da distinção mass/count em nível lexical em PB, sendo que essa distinção só se torna visível na interface mediante determinados ambientes sintáticos, decorre que a criança, ao adquirir a distinção mass/ count em PB, possivelmente tem de levar em conta não somente as informações contidas na interface fônica (como a presença de morfemas de número), mas também os traços semânticos da raiz dos nomes, principalmente no caso de DPs ambíguos, como DPs nus singulares. Desta forma, espera-se que, na aquisição da oposição massivo/contável em $\mathrm{PB}$, as crianças reconheçam a informação relativa a número, interpretando-a como indicativa de leitura contável, e que os traços semânticos da raiz nominal interfiram nessa interpretação, notadamente no caso de DPs ambíguos.

\section{Experimento sobre Percepção da Distinção Massivos e Contáveis em PB}

O experimento aqui mostrado investiga o papel das informações sintáticas e semânticas veiculadas no DP no processo de aquisição da distinção entre nomes massivos e contáveis em português brasileiro (PB), em especial as informações relativas à expressão do número gramatical. Com base no que se apresentou anteriormente, assume-se que, para o reconhecimento da distinção mass/count em PB, é importante a manifestação morfológica relativa a número que se manifesta nos elementos do DP. Desta forma, apresenta-se a hipótese de que uma criança, uma vez que seja capaz de perceber a presença/ausência do morfema de número, pode tomar a presença do morfema de número como indicativa de um DP contável. No que se refere à referência massiva, outros deverão ser levados em conta, considerando-se as particularidades do PB. Em PB, tem-se a presença de nomes nus singulares em posições argumentais, o que torna o input ambíguo no que se refere a mass e count nouns, isto é, a presença da flexão de número plural é indicativa de leitura contável, enquanto a forma singular é ambígua no que diz respeito à distinção mass/count. Além disso, diferentemente do inglês, em que a oposição entre os quantificadores many e much; é indicativa da distinção mass/ count (many > count; much > mass) tal oposição inexiste no PB, língua em que o quantificador muito pode receber leitura massiva ou contável (cf. NEVES, 2002). Para dirimir essas ambiguidades, pode-se assumir que a criança usa não apenas informação morfológica, mas sim semântica e/ou contextual, na interpretação de DPs ambíguos. Estas ambiguidades do estímulo ficariam mais evidentes no caso de nomes novos, constituindo-se em um problema para a criança que adquire o $\mathrm{PB}$. Assumindo-se que o 
PB é uma língua que apresenta distinção lexical entre massivos e contáveis, mas que essa distinção é visível apenas em ambientes marcados para contabilidade (cf. PARAGUASSU, 2005), pode-se imaginar que os traços semânticos da raiz dos nomes influenciam a criança na interpretação mass ou count de um DP em determinados contextos. Daí o experimento ora descrito valer-se de nomes inventados e de nomes conhecidos, estes últimos variando com relação a traços semânticos da raiz como mais favoráveis a leituras massivo ou contável, nos estímulos experimentais, justamente com vistas verificar uma possível influência de traços semânticos da raiz dos nomes na interpretação do DP.

Assim, os objetivos principais deste experimento foram i) verificar se a criança toma a presença do morfema de número como indicativa de leitura contável, ii) verificar se a presença do quantificador muito afeta a interpretação massiva ou contável de um DP, e iii) verificar uma possível influência dos traços semânticos da raiz lexical na interpretação massiva ou contável de um DP.

\section{Design Experimental}

O experimento foi concebido de modo a possibilitar duas análises. Na primeira, nomes inventados e nomes reais foram utilizados e estes últimos foram contrabalançados com relação à leitura preferencial sugerida por sua raiz. Assim, os nomes carro, bola, flor, botão, bife, bala, biscoito e batata foram considerados como sugestivos de leitura contável, enquanto que os nomes água, leite, café, feijão, manteiga, pão, doce e bolo, foram tomados como sugestivos de leitura massiva. Na segunda, apenas nomes reais foram utilizados e tipo de raiz passou a ser uma variável independente.

Para análise 1, as variáveis independentes foram:

Número: (singular) / (plural)

Tipo de DP: quantificado / não quantificado

Tipo de nome: real / inventado (Fator grupal)

Idade: 3 anos, 5 anos e adultos (Fator grupal)

Obteve-se, assim, um design fatorial 2 (número) $\times 2$ (tipo de DP) $\times 2$ (tipo de nome) $\times 3$ (idade) - os dois primeiros fatores são medidas repetidas (variáveis intra-sujeito) e os outros dois são fatores grupais (variáveis inter-sujeitos).

Para análise 2, as variáveis independentes foram:

Número: (singular) / (plural)

Tipo de DP: quantificado / não quantificado

Tipo de raiz: em função da leitura preferencial em PB: massivo / contável)

Idade: 3 anos, 5 anos e adultos (Fator grupal) 
Investigando as Habilidades de Processamento Linguístico Infantil:

A Aquisição da Distinção Massivo/Contável em Português Brasileiro

Tem-se assim um design fatorial: 2 (número) $\times 2$ (tipo de DP) $\times 2$ (tipo de raiz) $\times 3$ (idade), no qual os três primeiros fatores são medidas repetidas. Apresenta-se abaixo um exemplo de cada condição experimental:

\section{Grupo Real}

1. Singular quantificado: O Tito comeu muito pão/biscoito..

2. Singular não quantificado: O Tito comeu pão/biscoito.

5. Plural quantificado: O Tito comeu muitos pães/biscoitos

4. Plural não quantificado. O Tito comeu pães/biscoitos:

Grupo Inventado

1. Singular quantificado: O Tito comeu muito dube.

2. Singular não quantificado: O Tito comeu dube.

5. Plural quantificado: O Tito comeu muitos dubes.

4. Plural não quantificado: O Tito comeu dubes.

Foram apresentados quatro estímulos por condição experimental em cada grupo. A variável dependente foi o número de respostas correspondentes à indicação da imagem com mais de um elemento crítico (correspondente ao nome do DP em questão), doravante, respostas contáveis.

\section{Método}

Participantes: Dois grupos de crianças, o primeiro formado por 16 crianças ( 10 do sexo masculino e 6 do sexo feminino), de 20 a 36 meses de idade, com idade média de 32 meses, e o segundo formado por 16 crianças (8 do sexo masculino e 8 do sexo feminino), de 42 a 60 meses de idade, com idade média de 57 meses. As crianças de ambos os grupos eram todas filhas de pais escolarizados e regularmente matriculadas na rede particular de educação infantil, residentes na cidade de Petrópolis/RJ. Testaram-se, de igual modo, dois grupos formados por 16 adultos, com idades entre 17 e 39 anos (média de idade 37 anos), ambos constituídos de alunos de graduação matriculados em cursos noturnos da Universidade Católica de Petrópolis (UCP) e da Faculdade de Medicina de Petrópolis (FMP), que se apresentaram voluntariamente para participar do experimento .

\section{Material}

O material linguístico (estímulos) foi constituído de 16 frases, 4 por condição experimental, como exemplificado acima. O material visual foi criado a partir de fotografias de dois personagens (o Tito e a Duda), representados por dois jovens adultos, um do 
sexo masculino e outro feminino, ambos alunos da graduação em Letras da UCP. Fotos semelhantes desses personagens foram combinadas com desenhos de objetos a serem tomados como referentes dos DPs das frases-teste. Para cada frase foram apresentadas duas imagens com o mesmo personagem e diferentes quantidades de um mesmo tipo de objeto - um único exemplar e vários, sendo que o único exemplar foi sempre maior do que os vários apresentados. As fotografias foram apresentadas na tela de um laptop Compaq Presario V6210BR, com processador AMD Sempron 667 Mhz, memória RAM de 1 GB e HD de 60 GB.

\section{Procedimento}

Adotou-se o paradigma metodológico da Tarefa de Seleção de Imagens (Picture Identification Task) com nomes/objetos reais e inventados. O experimento foi precedido pela apresentação das fotos dos personagens em questão e familiarização com a tarefa. O experimento consistiu da apresentação concomitante das duas imagens correspondentes à condição em questão, seguida da apresentação do estímulo-teste por parte do experimentador, eliciando a escolha de uma das imagens, como resposta, por meio da diretiva do tipo, "Mostra pra mim o que o Tito/a Duda comeu". As imagens foram exibidas na tela de um computador portátil e as respostas anotadas, pelo experimentador, em uma ficha avaliação. $\mathrm{O}$ procedimento com crianças foi conduzido, individualmente, numa sala da escola/creche, com a presença da professora por perto. Este durou cerca de 15 minutos. O procedimento com adultos foi conduzido numa sala vazia da UCP e durou cerca de 10 minutos.

\section{Resultados}

Análise 1: As respostas contáveis obtidas foram submetidas a uma análise da variância (ANOVA) com design fatorial 2 (tipo de DP) $\times 2$ (número) $\times 2$ (tipo de nome) $\times 3$ (idade), onde tipo de nome e idade foram fatores grupais, e os demais medidas repetidas. Os efeitos principais dos seguintes fatores foram significativos: idade $(\mathrm{F}(2,90)=3.12 \mathrm{p}<.05)$, número $(\mathrm{F}(1,90)=179.55 \mathrm{p}<.0001)$, nome $(\mathrm{F}(1,90)$ $=5.28 \mathrm{p}=.02)$, e tipo de $\mathrm{DP}(\mathrm{F}(1,90)=50.23 \mathrm{p}<.0001)$. Os gráficos 1 a 4 apresentam as médias obtidas.

\section{Gráfico 1}

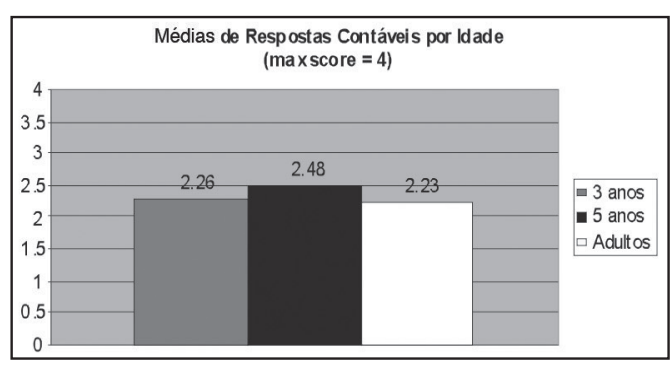


Investigando as Habilidades de Processamento Linguístico Infantil:

A Aquisição da Distinção Massivo/Contável em Português Brasileiro

O efeito de idade, como ilustrado pelo gráfico acima, atingiu o nível de significância $(\mathrm{p}<.05)$, com um aumento no número de respostas contáveis na idade de 5 anos, retornando, nos adultos, ao nível verificado na faixa de 3 anos. Cabe verificar, diante desses resultados, que fatores explicam a alteração de comportamento das crianças na faixa etária de 5 anos. Provavelmente, crianças nessa idade se valem de outro tipo de informação na atribuição de leitura mass ou count ao DP.

Gráfico 2

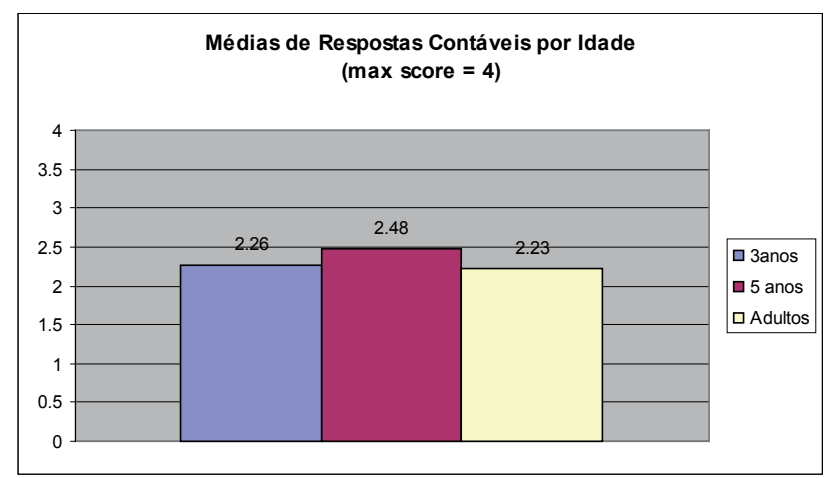

Do gráfico acima se depreende que, conforme o esperado, a presença do morfema de número induz leitura contável, já que se observou um maior número de respostas contáveis diante de um DP plural. Assim, pode-se afirmar que a criança toma a informação morfológica relativa a número como indicativa de leitura contável.

\section{Gráfico 3}

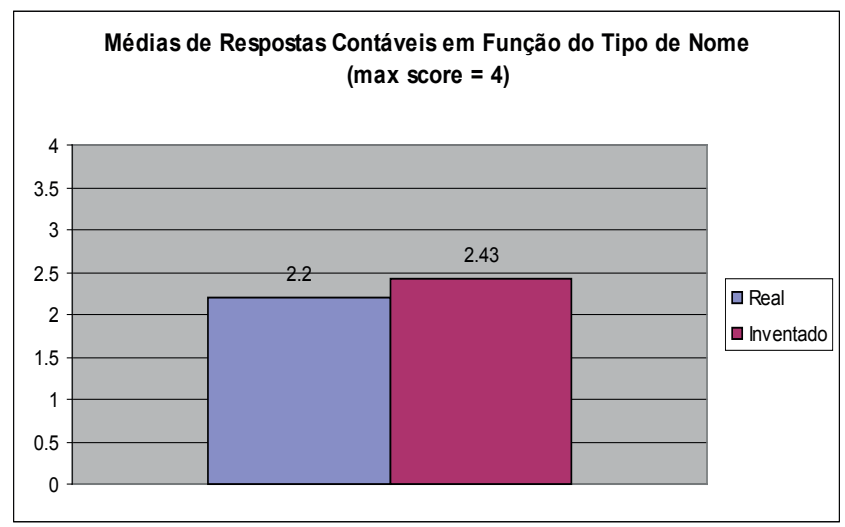

No que concerne à variável tipo de nome, constatou-se que os nomes inventados recebem maior quantidade de respostas contáveis do que os nomes reais. Uma possível explicação para tal fato é que, nos nomes inventados, não há influência dos traços 
semânticos da raiz, visto tratar-se de um nome desconhecido para crianças e adultos. Dessa forma, a informação morfológica se afigura como a informação mais relevante na interpretação massiva ou contável dos DPs. Isso sugere que, possivelmente, há uma influência dos traços semânticos da raiz na leitura do DP.

\section{Gráfico 4}

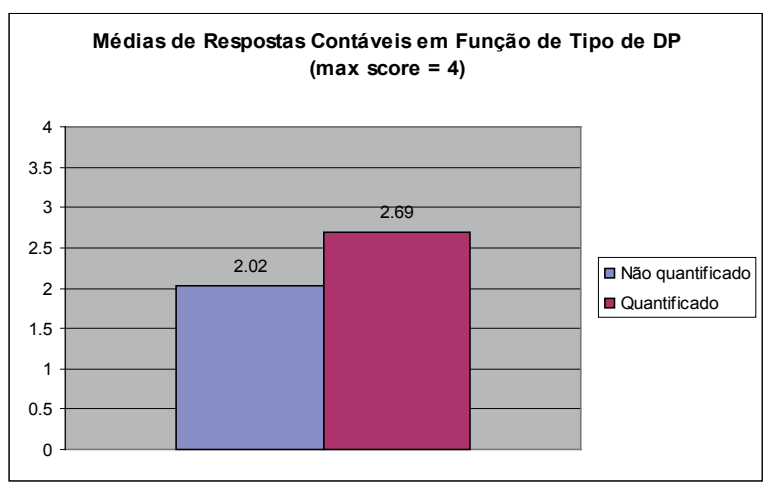

O gráfico 4 mostra uma diferença entre o número de respostas contáveis nas condições quantificado e não-quantificado. Isso permite a conclusão de que a presença do quantificador muito induz uma leitura contável do DP, apesar de poder receber, em alguns contextos, interpretação massiva Interações: Houve interação significativa entre as seguintes variáveis: número e idade $(\mathrm{F}(2,90)$ $=10.93 \mathrm{p}=.0001)$, número e nome $(\mathrm{F}(1,90)=11.83 \mathrm{p}=.001)$, tipo de DP e nome $(\mathrm{F}(1.90)=15.61 \mathrm{p}<.001)$, e número e tipo de $\mathrm{DP}(\mathrm{F}(1.90)=7.03$ $\mathrm{p}$ <.01). A interação entre número, tipo de DP e idade se aproximou do nível de significância $(\mathrm{F}(2.90)=2.84 \mathrm{p}=.06)$. Os gráficos 5 a 9 a seguir mostram as médias:

\section{Gráfico 5}

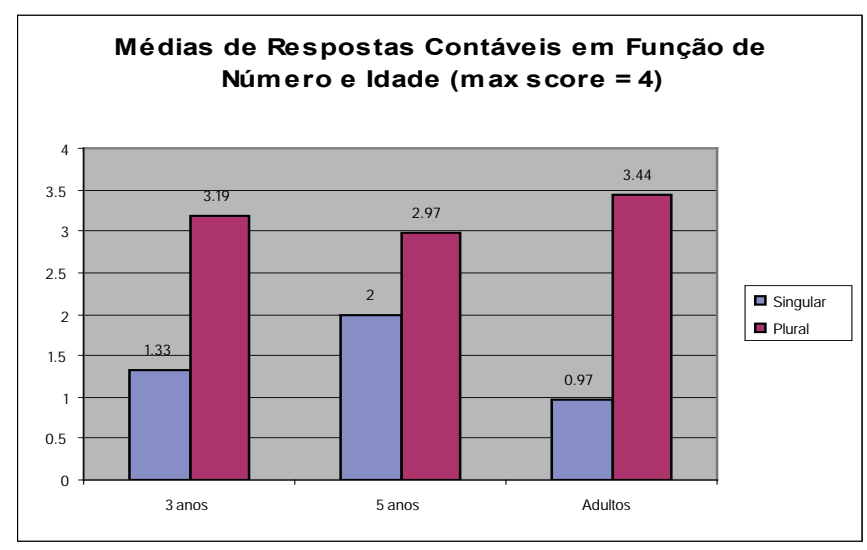

O gráfico 5 demonstra que o número de respostas contáveis na condição plural decresce aos 5 anos, tornando a subir nos adultos. Já o número de respostas contáveis na condição singular 
Investigando as Habilidades de Processamento Linguístico Infantil:

A Aquisição da Distinção Massivo/Contável em Português Brasileiro aumenta aos cinco anos e diminui nos adultos. Esses resultados evidenciam que os adultos parecem fazer uso mais consistente da informação morfológica de número, conferindo interpretação contável preferencialmente aos DPs marcados para plural, dando poucas respostas contáveis para DPs com nome no singular. Essa leitura pode ser devida à possibilidade de nomes nus singulares com interpretação plural em PB. O grupo de 3 anos apresenta um comportamento próximo ao dos adultos, sugerindo que crianças nesta faixa etária também fazem uso preferencial da informação morfológica de número. O grupo de crianças de 5 anos, por outro lado, faz menor uso da marcação de número, tendendo a interpretar nomes nus singulares como contáveis.

\section{Gráfico 6}

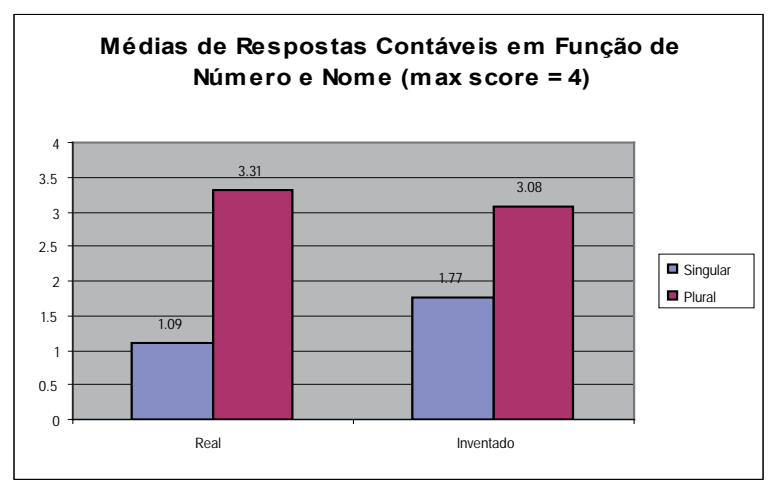

O gráfico 6 acima mostra que há um número maior de respostas contáveis na condição nome real plural, decaindo na condição nome inventado plural. No caso de nomes singulares reais, verifica-se que o número de respostas contáveis aumenta na condição singular inventado. Esses resultados evidenciam que o fato de os sujeitos conhecerem os nomes interfere na interpretação dada aos DPs, corroborando, assim, a influência dos traços semânticos da raiz evidenciada na análise da variável tipo de nome.

Gráfico 7

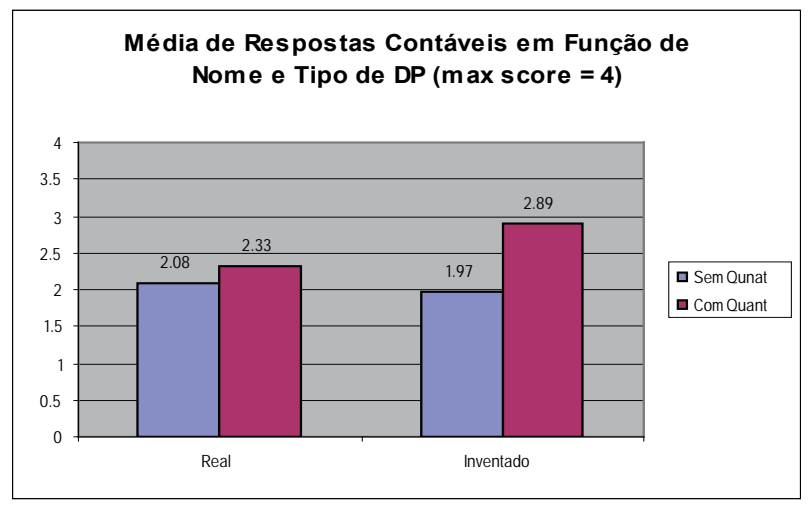


O efeito significativo registrado na interação entre nome e tipo de DP se explica pelo fato de a média de respostas contáveis na condição nome inventado com quantificador ser maior do que a da condição nome real com quantificador, com o inverso sendo verificado no cotejo entre o nome real não-quantificado e no nome real quantificado, em que se nota um decréscimo. Mais uma vez, nota-se uma influencia dos traços semânticos da raiz, que parecem ser levados em conta preferencialmente à presença do quantificador.

\section{Gráfico 8}

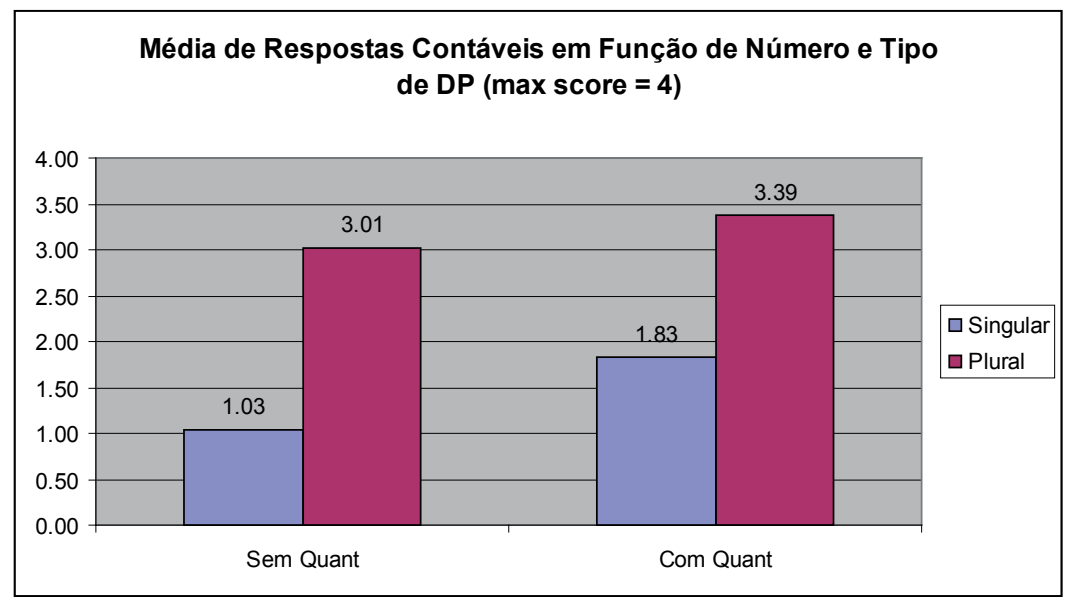

O número de respostas contáveis na condição com quantificador aumenta em relação à condição sem quantificador. Nos DPs singulares, o número de respostas contáveis na condição com quantificador sobe em relação ao apresentado na condição sem quantificador. A interação entre número e tipo de DP aponta que, quando há a presença do morfema de número, esta parece ser a informação preferencial. Na ausência do morfema de número, a presença do quantificador torna-se relevante, induzindo uma interpretação contável aos DPs quantificados. Esses resultados evidenciam que DPs singulares quantificados são mais facilmente interpretados como contáveis do que seu correlato não-quantificado, corroborando assim a afirmação de que, em PB, o quantificador muito recebe preferencialmente leitura contável.

O gráfico a seguir demonstra que a leitura contável na condição plural quantificado aumenta ligeiramente de acordo com a idade, constituindo assim uma tendência relativamente estável através das faixas etárias pesquisadas. Já o número de respostas contáveis na condição singular quantificado aumenta na faixa etária de 5 anos, decaindo nos adultos. A condição plural sem quantificador, ao contrário, cai aos 5 anos, subindo novamente nos adultos, com a condição singular sem quantificador aumentando aos 5 anos e sofrendo uma queda acentuada nos adultos. Assim, 
Investigando as Habilidades de Processamento Linguístico Infantil:

A Aquisição da Distinção Massivo/Contável em Português Brasileiro

a sensibilidade à presença do morfema de número é maior aos 3 anos e nos adultos do aos 5 anos, com a sensibilidade à presença do quantificador maior aos 5 anos do que aos 3 anos e nos adultos. Os resultados fornecem evidências de que a quantificação induz leitura contável, e que a presença da informação relativa a número é crucial na interpretação massiva ou contável do DP.

\section{Gráfico 9}

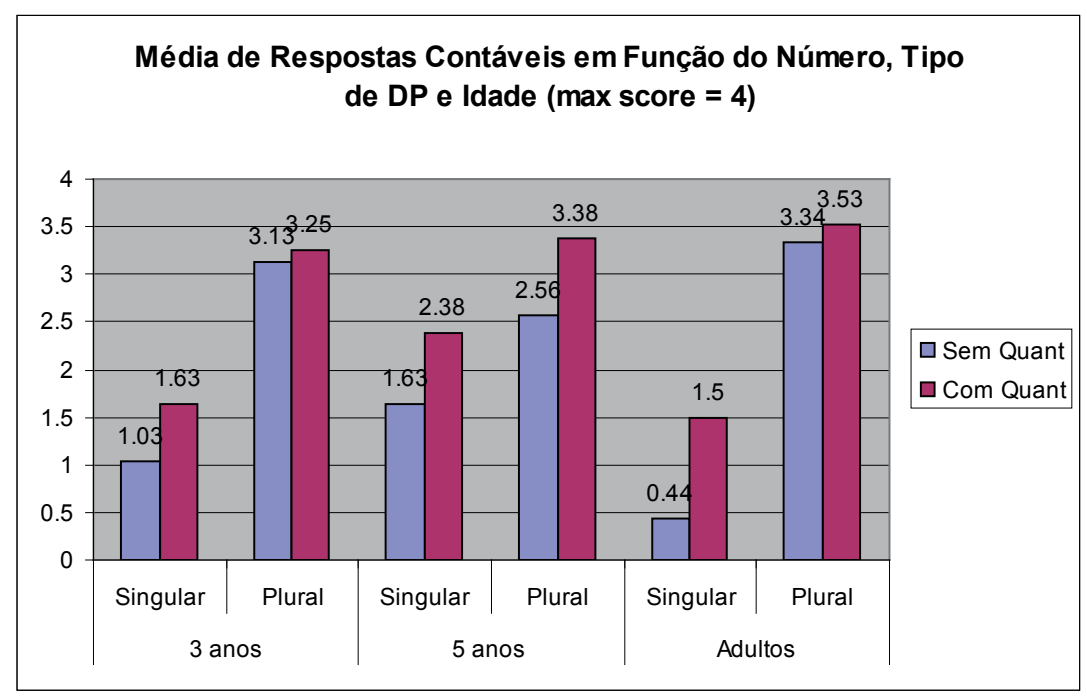

Discussão:

Concluindo, o que a análise 1 mostra é que a informação do morfema de número é fundamental para interpretação massiva ou contável, e que a presença do quantificador de fato é indicativa de leitura contável, ainda que possa haver contextos em que o quantificador muito sugere leitura massiva (cf. Neves, 2002). Entretanto, os resultados indicam, como antecipado, uma possível influência dos traços semânticos da raiz. A fim de verificar o quanto essa influência se faz presente, foi realizada a análise 2 .

Análise 2: Apenas os dados do grupo Nome conhecido foram analisados por meio de uma análise da variância (ANOVA) com design fatorial 2 (tipo de DP) $\times 2$ (número) $\times 2$ (tipo de raiz) $\times 3$ (idade), onde idade é um fator grupal e os demais medidas repetidas. Os efeitos principais dos seguintes fatores foram significativos: número $(\mathrm{F}(1,45)=105,62 \mathrm{p}<.00001)$ tipo de $\mathrm{DP}(\mathrm{F}(1,45)=17,52$ $\mathrm{p}<. .0001)$ e tipo de raiz $(\mathrm{F}(2,45)=4,28 \mathrm{p}<.000001)$. O efeito de idade aproximou-se do nível de significância $(\mathrm{F}(2,45)=2,82 \mathrm{p}<.06)$. Os gráficos 10 a 12 apresentam as médias obtidas.

Como pode ser observado no gráfico 10 , como seria esperado, a presença do morfema de número induz à leitura contável, visto houve mais respostas contáveis diante de um DP plural. 


\section{Gráfico 10}

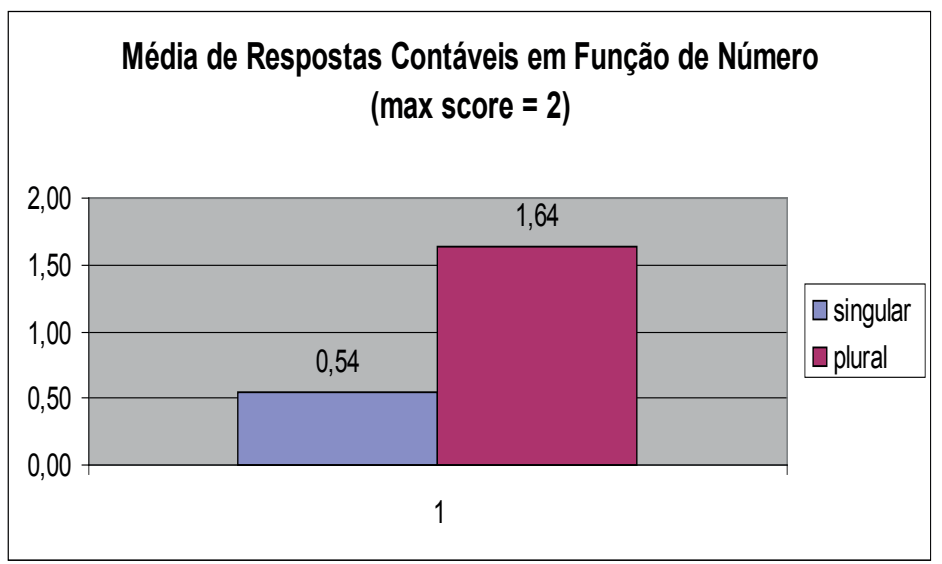

Observa-se no gráfico 11 que a presença do quantificador muito induz uma leitura contável do DP, o que torna um DP quantificado, de uma forma geral, menos ambíguo em relação a massividade/contabilidade do que um DP singular não quantificado. A possibilidade de nomes nus singulares no PB favorece, assim, a leitura de um DP do tipo comeu muito biscoito como contável.

\section{Gráfico 11}

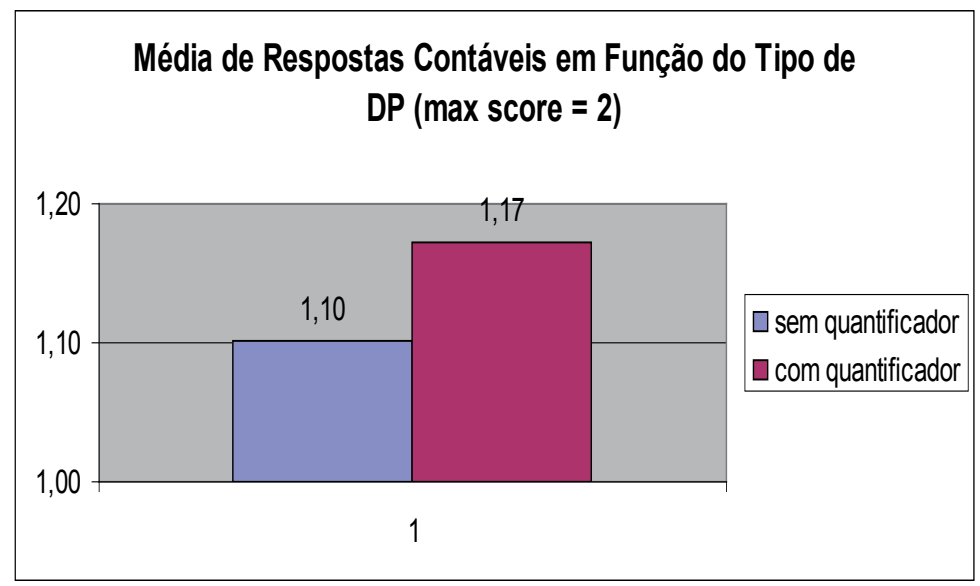

O fato de tipo de raiz apresentar resultado significativo sugere que adultos e crianças em fase de aquisição do PB são sensíveis aos traços semânticos da raiz, e certamente usam essas informações semânticas na interpretação de DPs ambíguos. Aqueles nomes considerados como favorecedores de uma leitura contável realmente induziam mais respostas contáveis do que os nomes inicialmente categorizados como massivos. 
Gráfico 12

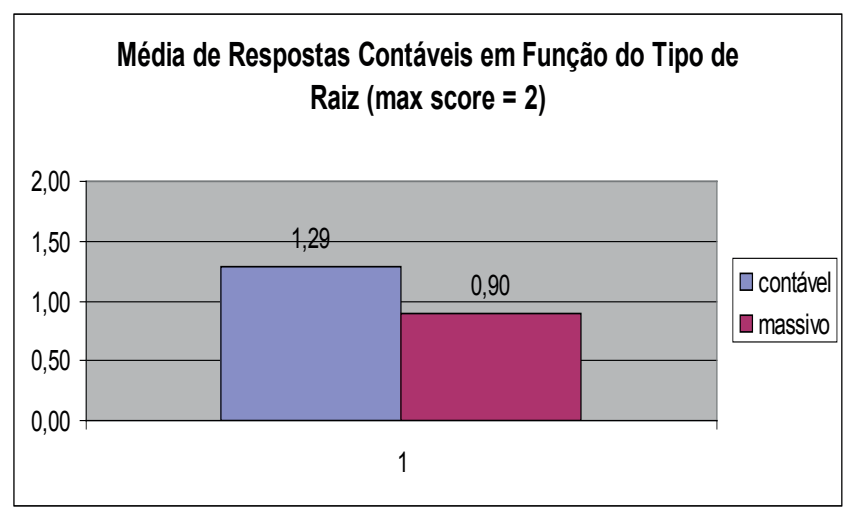

O efeito de idade, como demonstra o gráfico 13, aproximouse do nível de significância. O número de respostas contáveis é menor no grupo de adultos, possivelmente decorrente de leitura massiva. O grupo de 3 anos produz um número um pouco maior de respostas contáveis, embora não seja claro, por esse resultado, se a estratégia de interpretação do DP é semelhante entre este grupo e o de adultos. O efeito significativo da interação entre Número e idade poderá clarificar este resultado.

\section{Gráfico 13}

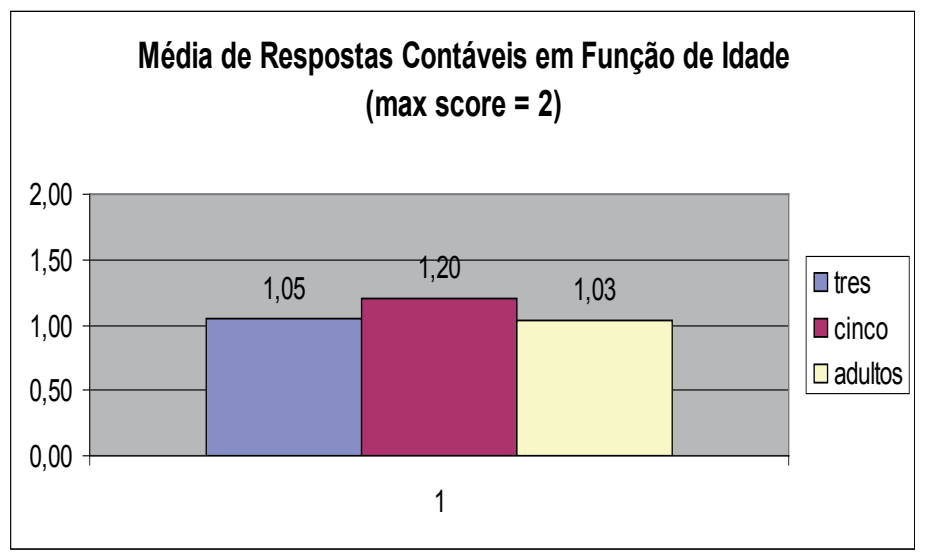

Interações: Houve interação significativa entre as seguintes variáveis: número e idade $(\mathrm{F}(2,45)=7,99 \mathrm{p}<.001)$, tipo de DP e idade $(\mathrm{F}(2,45)=5,05 \mathrm{p}<.01)$, número e tipo de $\mathrm{DP}(\mathrm{F}(1,45)=5,32 \mathrm{p}=.02)$, idade e tipo de raiz $(\mathrm{F}(2,45)=4,01 \mathrm{p}=.03)$ e idade, tipo de raiz e número $(\mathrm{F}(2,45)=4,28 \mathrm{p}=.02)$. A interação entre número e raiz aproximou-se do nível de significância $(F(1,45)=3.07 \mathrm{p}=.08)$. Os gráficos 14 a 18 a seguir mostram as médias: 


\section{Gráfico 14}

Média de Respostas Contáveis em Função de Número e

Idade

(max score $=2)$

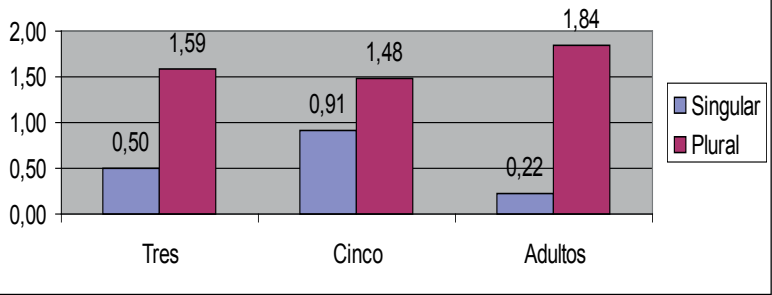

O gráfico 14 demonstra que enquanto o número de respostas contáveis na condição plural diminui ligeiramente no grupo de 5 anos, este cresce no grupo de adultos. O número de respostas contáveis na condição singular, por outro lado, cresce aos cinco anos e decresce consideravelmente no grupo de adultos. Observa-se que no grupo de 5 anos, a diferença entre o número de respostas contáveis na condição singular e plural é menor do que esta diferença no grupo de 5 anos e bem menor do que a mesma no grupo de adultos. Esses resultados evidenciam que os adultos parecem fazer uso mais consistente da informação morfológica de número, conferindo interpretação contável preferencialmente aos DPs marcados para plural, dando poucas respostas contáveis para DPs com nome no singular. Essa leitura pode ser devida à possibilidade de nomes nus singulares com interpretação plural em PB. O grupo de 3 anos apresenta um comportamento próximo ao dos adultos, sugerindo que crianças nesta faixa etária também fazem uso preferencial da informação morfológica de número. O grupo de crianças de 5 anos, por outro lado, faz menor uso da marcação de número, tendendo a interpretar nomes nus singulares como contáveis.

\section{Gráfico 15}

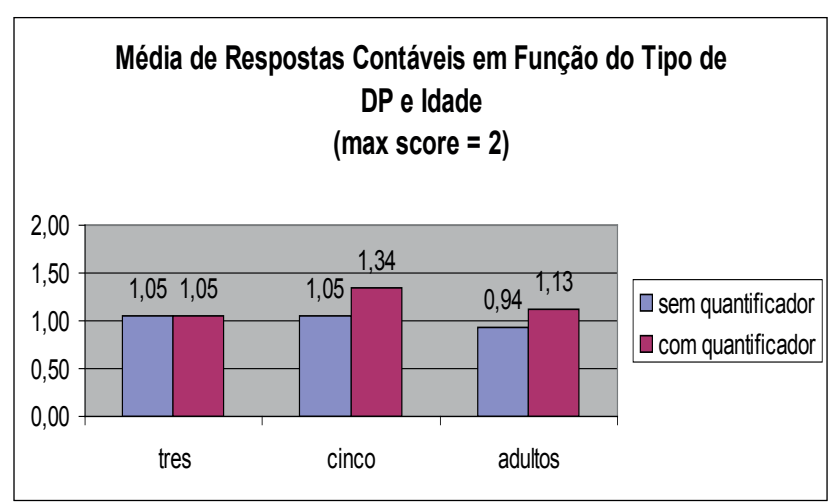


Investigando as Habilidades de Processamento Linguístico Infantil:

A Aquisição da Distinção Massivo/Contável em Português Brasileiro

Os resultados acima indicam que o número de respostas contáveis para DPs sem quantificador permanece estável nas três faixas etárias pesquisadas. O número de respostas contáveis em DPs quantificados, contudo, aumenta aos cinco anos e decai consideravelmente nos adultos. Esses resultados revelam que as crianças de 3 anos não levam em conta a presença do quantificador, ao passo que as crianças de 5 anos parecem tomar a presença do quantificador como relevante para a leitura massiva/contável. Os adultos parecem conferir menor relevância a esse fator, na interpretação dos DPs.

\section{Gráfico 16}

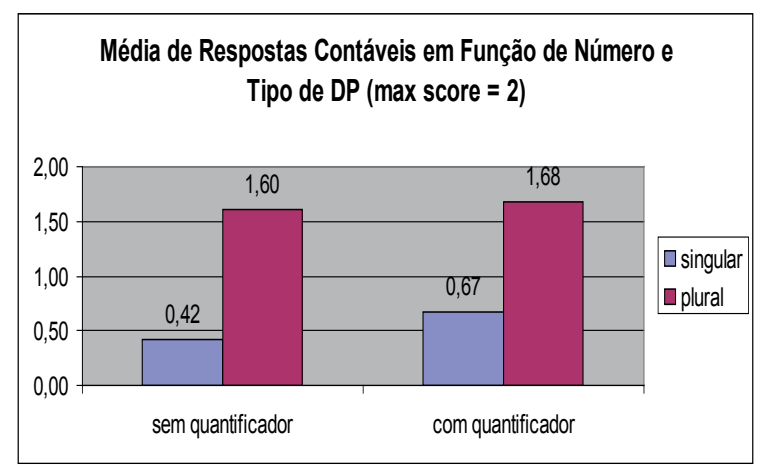

O número de respostas contáveis na condição com quantificador é próximo ao da condição sem quantificador. Já nos DPs singulares, o número de respostas contáveis na condição com quantificador é maior do que o apresentado na condição sem quantificador. A interação entre número e tipo de DP mostra que, quando há a presença do morfema de número, esta parece ser a informação preferencial. Quando não há a presença do morfema de número, a presença do quantificador torna-se relevante, induzindo uma interpretação contável aos DPs quantificados. Esses resultados evidenciam que DPs singulares quantificados são mais facilmente interpretados como contáveis do que seu correlato não-quantificado, corroborando assim a afirmação de que, em PB, o quantificador muito recebe preferencialmente leitura contável.

\section{Gráfico 17}

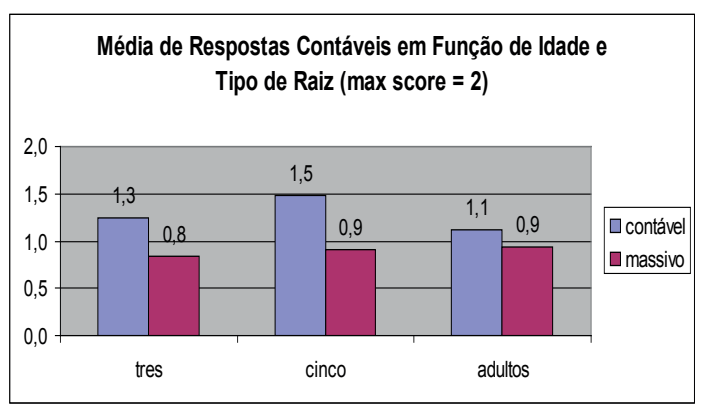


O número de respostas contáveis para raízes massivas permaneceu constante nas três faixas etárias pesquisadas; nas raízes contáveis, no entanto, observou-se um aumento na faixa etária de 5 anos, decaindo nos adultos. A influência da raiz contável, por conseguinte, parece ser maior aos 5 anos, o que conduz à conclusão de que as crianças nesta idade conferem maior relevância à informação semântica da raiz. Os resultados mostrados pelo gráfico 22, os quais mostraram que crianças de 5 anos fazem menor uso da marcação de número, podem ser explicados pelos resultados da interação entre idade e tipo de raiz, na medida em que se evidenciou uma preferência da criança de 5 anos pela informação semântica, em detrimento da informação morfológica.

Gráfico 18

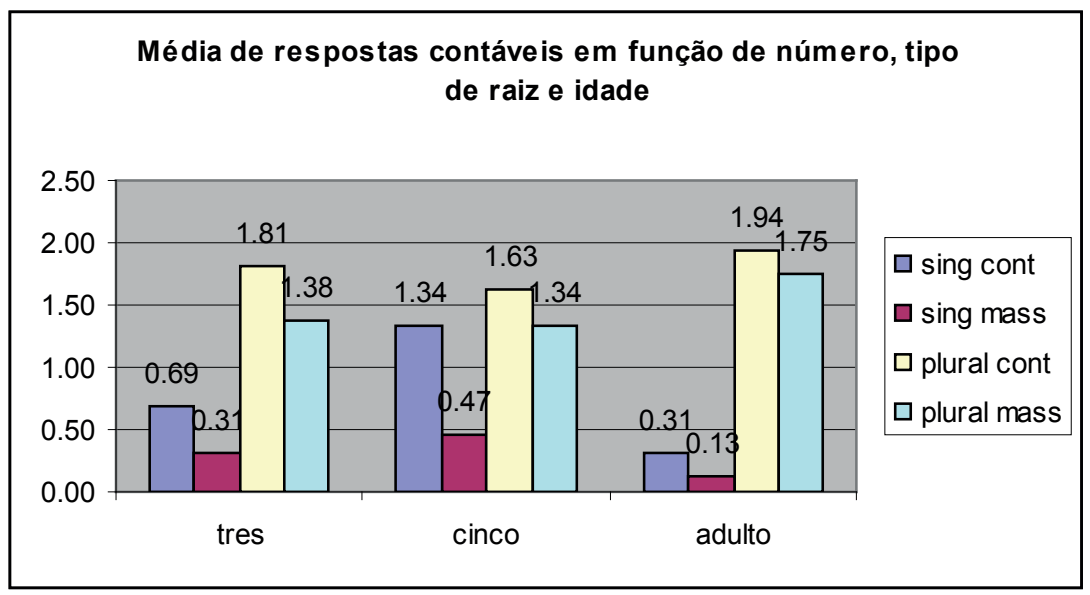

No que se refere à interação entre idade, tipo de raiz e número, observa-se que o comportamento do grupo de três anos e do de adultos apresenta um padrão semelhante, ainda que o número de respostas contáveis para DPs plural seja maior no grupo de adultos. O padrão de comportamento do grupo de 5 anos, contudo, é distinto, uma vez que há um número consideravelmente grande de respostas contáveis para DPs singulares de raiz contável. Crianças de 5 anos parecem, portanto, ser mais afetadas pelos traços semânticos da raiz, o que sugere ser essa informação a preferida diante da possibilidade de nomes singulares nus com leitura plural no PB.

\section{Discussão:}

Os resultados da análise 2 evidenciam que há uma influência dos traços semânticos da raiz na interpretação massiva ou contável do DP. Essa influência é mais nítida no caso de DPs nus singulares, que são ambíguos para mass/count. No caso de DPs marcados morfologicamente para número, é a informação expressa pelo morfema que parece ser a preferencial, sendo 
indicativa de leitura contável do DP. A interferência dos traços massivo/contável da raiz nominal pode ocorrer na interpretação de nomes nus ou precedidos por muito em DPs objetos, indicando mass ou count, como ilustram os exemplos João comeu bolo/muito bolo (admite leitura massiva ou contável) e João leu livro/muito livro e viu filme/muito filme (que parece só admitir leitura count). A preferência pelas informações semânticas parece ser maior aos cinco anos, ao passo que crianças de 3 anos e adultos fazem uso preferencial de informação advinda da morfologia.

\section{Conclusões:}

Quanto aos objetivos estabelecidos para este experimento, os resultados por ele obtidos permitem afirmar que a criança toma a presença do morfema de número como indicativa de leitura contável, o que faz da informação relativa a número um fator importante na interpretação massiva ou contável de um DP. No que concerne ao quantificador muito, ainda que ele possa receber leitura massiva ou contável em PB (cf. NEVES, 2002), é essa última que se faz preferencialmente, em especial para crianças em fase inicial de aquisição (até 3 anos). A afirmação de que a informação morfo-fonológica relativa a número é crucial na aquisição de mass/count nouns se aproximaria da visão defendida pelas linhas gramatical e contextual no estudo da aquisição da distinção mass/ count, conforme aqui mostrado e discutido. Entretanto, os resultados mostram que informações de natureza gramatical não são as únicas a serem levadas em conta - uma vez que o experimento registrou uma influência dos traços semânticos da raiz, pode-se concluir que a criança se utiliza de informação de natureza semântico-conceptual. Assim, pode-se conceber a aquisição da distinção mass/count de uma forma unificada, na qual a criança usaria, em uma fase inicial de aquisição preferencialmente informação de ordem gramatical (morfema de número), sendo, no entanto, sensível aos traços semânticos da raiz nominal. Essa sensibilidade torna-se acentuada aos 5 anos de idade, quando a criança busca outras fontes de informação diante de DPs ambíguos quanto à distinção mass/count, particularmente os DPs singulares, Esta informação adicional pode ser extraída tanto da raiz nominal quanto do quantificador muito que, nessa faixa etária, é preferencialmente interpretado como indicativo de leitura contável.

Para o PB, pode-se esboçar a expressão de mass/count nouns com base no seguinte: nomes nus singulares em posição de objeto recebem interpretação genérica ou massiva (como em "João comprou batata"), com os nomes precedidos pelo quantificador muito na mesma posição ("João comprou muita batata") recebendo preferencialmente leitura contável. Uma vez que se achem flexionados em número, com a presença do morfema de plural, nomes nus, determinantes e quantificadores sempre receberão interpretação contável ("João comprou batatas/as batatas/umas batatas/muitas bata- 
tas"). Os resultados do experimento permitem sustentar a hipótese de que uma criança, ao adquirir a distinção mass/count em PB seja capaz de, em primeiro lugar, perceber a presença/ausência do morfema de número nos nomes, tomando esta oposição como indicativa de expressão contável. Tem-se, assim, em um primeiro momento, um processo de aquisição de base gramatical-contextual, sendo que, em um outro momento, a criança lançaria mão de informação de natureza semântica, notadamente em casos em que o material linguístico apresenta-se de modo ambíguo.

A criança que adquire o PB tem de diferenciar um DP plural verdadeiramente count (ou seja, um DP que contenha um nome que possua partes mínimas em sua denotação) de um DP plural sob o escopo de um operador de contabilidade (ou seja, um DP que contenha um nome que não possua partes mínimas em sua denotação, mas que esteja sendo usado como um nome count). Exemplificando, é como se a criança adquirindo a distinção mass/ count tenha de perceber a diferença entre João comprou os carros da loja e João desviou as águas do rio. Uma outra questão é a interpretação mass ou count de DPs como João comeu bolo/muito bolo (admite leitura massiva ou contável) e João leu livro/muito livro e viu filme/muito filme (que parece só admitir leitura count). Conforme se percebe, tanto nomes singulares quanto morfologia de plural podem apresentar ruídos durante a aquisição da distinção mass/ count em PB. A ambiguidade do input pode tornar o processo de aquisição não tão óbvio, exigindo que a criança lance mão de outro tipo de informação que não a morfológica. Os resultados aqui relatados sugerem que esta informação acessória pode ser semântica, proveniente dos traços semânticos da raiz nominal, à qual a criança recorreria nos casos em que o estímulo apresentasse ruídos ou ambiguidades.

O processo de aquisição da distinção massivo/contável é um processo que se dá seguindo dois caminhos. Um, que consiste na fixação da denotação dos nomes, e que concerne ao modo como a realidade extralinguística é conceptualizada na língua, estando, portanto, sob a alçada de uma teoria do desenvolvimento cognitivo; e outro, que consiste na percepção, por parte da criança, da maneira como a distinção mass/count se faz visível nas interfaces fônica e semântica, dizendo assim respeito ao modo como unidades linguisticamente relevantes são processadas e interpretadas; estando, por conseguinte, sob o escopo de uma teoria de aquisição de linguagem calcada em informação linguística.

Portanto, o processo de aquisição da distinção entre nomes massivos e contáveis pode ser tratado tanto do ponto de vista de uma teoria de aquisição baseada em informação de ordem gramatical, quanto do ponto de vista de uma teoria de aquisição da língua mais diretamente vinculada ao desenvolvimento cognitivo (a qual se voltaria para o modo como determinadas informações são conceptualizadas). Nesse sentido, o estudo da aquisição da 
Investigando as Habilidades de Processamento Linguístico Infantil:

distinção entre nomes massivos e contáveis, na forma como aqui apresentada, ilustra a possibilidade de elaboração de uma teoria de aquisição da linguagem que articule teoria linguística, teoria psicolinguística e teorias do desenvolvimento cognitivo, mostrando de que o modo como a criança processa informação relevante presente nas interfaces e as associa com informações advindas de outros domínios da cognição.

\begin{abstract}
This study investigates the role of syntactic and semantic information present in the linguistic input in the acquisition of the distinction between count and mass nouns in Brazilian Portuguese (BP), specially the information expressed by grammatical number. It is assumed that, for the recognition of the distinction mass / count in PB, the grammatical number morphologic manifestation expressed in the elements of the Determiner Phrase (DP) is crucial. It can be assumed the hypothesis that the child is able to sense the presence / absence of number morpheme, and she takes this opposition as an indicator of mass or count noun. Moreover, the presence of bare nouns in argument positions in $\mathrm{PB}$ makes the input ambiguous with regard to mass and count nouns. This situation constitutes a problem for the child who acquires the PB. In this case, it is assumed the hypothesis that the child uses no morphological information, but semantic (contextual), the DP's interpretation of ambiguous. The objectives of this study are a) whether the child takes the presence of the morpheme as indicative of the count noun reading, and b) to see how the child proceeds to the interpretation of ambiguous DP's. Using the Picture Identification Task methodological paradigm, two groups of children (in a range of average age 36 months, and another in the range of 60 months) and a group of adults was tested. The results supports the idea that both morphosyntactic and semantic-contextual information are relevant in the acquisition of mass and count nouns in PB.
\end{abstract}

Keywords: acquisition, countable, mass distinction. 


\section{REFERÊNCIAS}

AUGUSTO, M. R. A. ; CORREAA, L. M. S. Genericity and bare nouns in the acquisition of Breazilian Portuguese. In: GALA 2007 - Generative Approaches to Language Acquisition, 2008, Barcelona. The proceedings of GALA 2007, edited by Anna Gavarró and M. João Freitas. Cambridge : Cambridge Scholars Publishing, 2007.

AUGUSTO, M. R. A. ; CORRÊA, L. M. S. . Marcação de gênero, opcionalidade e genericidade: processamento de concordância de gênero no DP aos dois anos de idade. Linguística (PPGL/UFRJ), Rio de Janeiro, v. 1, n. 2, p. 207-234, 2005.

AUGUSTO, M. R. A. ; FERRARI NETO, J. ; CORREAA, L. M. S. . Explorando o DP: a presença da categoria Num. Revista de Estudos da Linguagem, v. 14, p. 245-276, 2006.

BARNER, D. \& SNEDEKER, J. Children's early understanding of mass count individuation: lexical content, and the number asymmetry hypothesis. Harvard University. Departament of Psychology, 2005a. Disponível em http:// www.wjh.harvard.edu/ lds/ pdfs/barner2005. pdf. Acesso em 23 abr. 2006.

BARNER, D. SNEDEKER, J. Mapping Individuation to Mass-Count Syntax in Language Acquisistion. Harvard University. Departament of Psychology, 2005b. Disponível em www.cogsci.northwestern. edu/cogsci2004/papers/paper408.pdf. Acesso em 23 abr. 2006.

BLOOM, P. Semantic Structure and Language Development. Psychology.MIT Press, 1990.

BLOOM, P. Possible Names: the role of syntax-semantics in the acquisition of nominals. Lingua, 92, 1994.

BLOOM, P. Controversies in Language Acquisition: word learning and the part of speech. In: Perceptual and Cognitive Development. Academic Press, 1996.

BLOOM, P. \& WYNN, K. Linguistics Cues in the Acquisition of Number Words. Journal of Child Language, v.24, n 3, 1997

BLUHDORN, H. \& FAVARETTO, B. Contabilidade de Substantivos no português do Brasil. Estudos Linguísticos (GEL), vol. 29, 2000.

BLUHDORN, H.; SIMÕES, L. \& SCHMALTZ, M. Sintagmas Nominais Contáveis e Não-Contáveis no Alemão e no Português Brasileiro. A ser publicado em NOMURA, M. Estudos Contrastivos Alemão e Português do Brasil. São Paulo, 2007.

BROWN, R. A first language: the early stages. London: George Allen \& Unwin Ltd., 1973.

CAMACHO, R.G. \& PEZATTI, E.G. As subcategorias nominais contável e não-contável. In: KATO, Mary A. (org.). Gramática do Português Falado. vol. 5. Campinas: Editora da Unicamp, 1996.

CHENG, C.Y. Response to Moravcsik. In: Hintikka et. al. (eds.) Approaches to Natural Language, 1973. 
CHIERCHIA, G. Reference to Kinds across Languages. Natural Language Semantics 6.1998

CHIERCHIA, G. Language, Thought and Reality after Chomsky. Milan. University of Milan-Bicocca. 2003. Disponível em http://schlenke. bol.ucla.edu/Chierchia.pdf . Acesso em 04 abr. 2007.

CORRÊA, L. M. S. Aquisição da Linguagem e Problemas do Desenvolvimento Linguístico: Apresentação. In: Corrêa, L. M. S.. (Org.). Aquisição da Linguagem e Problemas do Desenvolvimento Linguístico. Rio de Janeiro: Editora da PUC-Rio/Edições Loyola, 2006, v. , p. 9-18. CORREAA, L. M. S. Conciliando processamento linguístico e teoria de lingua no estudo da Aquisição da Linguagem. In: CORRÊA, L. M. S.. (Org.). Aquisição da Linguagem e Problemas do Desenvolvimento Linguístico. Rio de Janeiro: Editora da PUC-Rio/Ediçoes Loyola, 2006, v. , p. 21-78.

CORREAA, L. M. S. O que, afinal, a criança adquire ao adquirir uma lingua? A tarefa da aquisição da linguagem em três fases e o processamento de informação de interface pela criança. Letras de Hoje, v. 42, p. 7-34, 2007.

CORREAA, L. M. S. Possíveis diálogos entre Teoria Linguística e Psicolinguistica: questões de processamento, aquisição e do Déficit Específico da Linguagem. In: N. MIRANDA; NAME, M.C.L. (Orgs.). Linguística e Cognição.. Juiz de Fora: Editora da UFJF, 2005, v. , p.221-244.

CORREAA, L. M. S. ; AUGUSTO, M. R. A. ; FERRARI NETO, J. . The Early Processing of Number Agreement in the DP: Evidence from the Acquisition of Brazilian Portuguese. In: 30 th Annual Boston University Conference on Language Development (BUCLD 30), 2006, Boston. BUCLD 30. Somervilles, Mass : Cascadilla Press, 2006. v. 2. CORREAA, L. M. S. ; FERRARI NETO, J. ; Name, M.C.L. . O Processamento da Informação de Interface na Aquisição do Sistema de Número Gramatical no DP em Português Brasileiro. In: VI Encontro nacional sobre Aquisição da Linguagem, 2003, Porto Alegre. Letras de hoje, 2003. v. 39. p. 123-137.

CORREAA, L. M. S. ; Name, M.C.L. Delimitação Perceptual de uma Classe Correspondente à Categoria Funcional D: Evidencias da Aquisição do Português. Forum linguístico, Florianópolis, v. 3, n. 1, p. 55-88, 2003. CORREAA, L. M. S. ; Name, M.C.L. The Processing of Determiner - Noun Agreement and the Identification of the Gender of Nouns in the Early Acquisition of Portuguese. Journal of Portuguese Linguistics, Portugal, v. 2, n. 1, p. 19-43, 2003.

CORREAA, L. M. S. ; Name, M.C.L. ; FERRARI NETO, J. . Explorando Informação de Interface na Aquisição da Linguagem: Distinções Perceptuais e Morfo-fonológicas relativas à Categoria Funcional na Aquisição de Gênero e Número em Português. In: III Congresso Internacional da ABRALIN (Associação Brasileira de Linguística), 2003, Rio de Janeiro. Anais do III Congresso Internacional da ABRALIN, 2003. p. 515-521. 
CORRÊA, L. M. S. ; Name, M.C.L. ; FERRARI NETO, J. . Explorando informação de Interface na Aquisição da Linguagem: Distinções Perceptuais e Morfo - fonológicas relativas à Categorias Funcional na Aquisição de Gênero e Número em Português. In: III Congresso Internacional da ABRALIN, 2003. Anais do III Congresso Internacional da ABRALIN, 2003. p. 515-521.

CORRÊA, L. M. S. ; Name, M.C.L. ; FERRARI NETO, J. . O processamento de informação de interface na aquisição de gênero e de número no português brasileiro. Letras de Hoje, Porto Alegre, v. 39, n. 3, p. 123-137, 2004.

CORREAA, L. M.S. Bootstrapping language acquisition from a minimalist standpoint: on the identification of phi-features in Brazilian Portuguese.2008, no prelo.

CORRÊA, L. M. S., NAME, M. C. L.\& FERRARI-NETO, J. Explorando Informação De Interface Na Aquisição Da Linguagem: Distinções Perceptuais E Morfo-Fonológicas Relativas À Categoria Funcional D Na Aquisição De Gênero E Número Em Português. Paper a ser publicado nos Anais do II Congresso Internacional da ABRALIN. 2003

FERRARI-NETO, J. Reconhecimento do número gramatical e processamento da concordância de número no sintagma determinante na aquisição do português brasileiro. Dissertação de Mestrado. PUC-Rio. 2003.

FERRARI NETO, J. ; CORRÊA, L. M. S. AUGUSTO, M. R. A. .O Processamento da Informação de Interface na Aquisição do Sistema de Número gramatical no DP em Português Brasileiro. In: IV Congresso Internacional da ABRALIN, 2005, Brasília. Anais do IV Congresso Internacional da ABRALIN, 2005. p. 1075-1082.

GATHERCOLE, V. He has too much hard questions: the acquisition of the linguistics mass-count distinction in much and many. Journal of Child Language, 12, 1985.

GATHERCOLE, V. Evaluating Competing Linguistic Theories with child language data: the case of the mass-count distinction. Linguistics and Philosophy, 9, 1986.

GORDON, P. Early encoding of the count/mass distinction: semantic or syntactic? Papers and Reports on Child Language Development, 1982.

GORDON, P. Evaluating the semantic categories hypothesis: the case of count/mass distinction. Cognition, 20, 1985.

GUY, Gregory R. Linguistic variation in Brazilian Portuguese: aspects of the phonology, syntax, and language history. 1981. 391p. Tese (Doutorado em Linguística) - University of Pennsylvania, Philadelphia,1981.

HUBACK, A.P.S. Efeitos de Frequência nas Representações Mentais. Tese de Doutorado. UFMG, 2007.

JOOSTEN, F. Accounts of the Count-Mass Distinction: A Critical Survey. Proceedings of the 19th Scandinavian Conference of Linguistics, vol. 31, 2003. 
MACNAMARA, J. Names for Things. MIT Press, 1982.

MACNAMARA, J. \& REYES, G.E. Foundational Issues in the Learning of Proper Names, Count Nouns and Mass Nouns. In: MACNAMARA, J. \& REYES, G.E. The logical foundations of cognition. MIT Press. 1994. MCPHERSON, L.M.P. A "little" goes the way: evidence for a perceptual basis of learning noun categories COUNT and MASS. Journal of Child Language, 18, 1991.

MIDDLETON, E.; WISNIEWSKI, E.; TRINDEL, K. \& IMAI, M. Separating the chaff from the oats: evidence for a conceptual distinction between count noun and mass noun aggregates. Journal of Memory and Language, 50, 2004.

MULLER, A.L. Genericity and the Denotation of Common Nouns in Brazilian Portuguese. D.E.L.T.A., vol. 18, n² 2, 2002.

NEVES, M.H.M. Gramática de Usos do Português. São Paulo: Editora UNESP, 2000.

NICOLAS, D. Count Nouns, Mass Nouns and their acquisition - A Psychological Investigation. Department of Psychology, McGill, Montreal, 1996. Disponível em http://d.a.nicolas.free.fr/research/ Nicolas.MN.CN.Acquisition.pdf. Acesso em 14 nov. 2006.

PARAGUASSU, N. Traços da Distinção Contável-Massivo no Chinês e no Português. Estudos Linguísticos, 34, 2005.

QUINE, W. Word and Object. Cambridge: MIT Press, 1960.

SIMÕES, L. Aquisição da distinção semântica entre nominais contáveise não-contáveis em língua portuguesa. Dissertação de Mestrado. Porto Alegre: PUCRS,1992. 